\title{
Syndrome of Apparent Mineralocorticoid Excess
}

\author{
A Defect in the Cortisol-Cortisone Shuttle
}

P. M. Stewart, J. E. T. Corrie, ${ }^{*}$ C. H. L. Shackleton, ${ }^{\ddagger}$ and C. R. W. Edwards
Department of Medicine and ${ }^{*}$ Medical Research Council Clinical \& Population Cytogenetics Unit, Western General Hospital,
Edinburgh EH4 $2 X U$ Scotland; and ${ }^{\ddagger}$ Children's Hospital Medical Center of Northern California, Oakland, California 94609

\section{Abstract}

The first adult case of $11 \beta$-hydroxysteroid dehydrogenase (11 $\beta$-OHSD) deficiency is described. The impaired conversion of cortisol to cortisone (indicated by urinary cortisol and cortisone metabolites and failure to metabolize $11 \alpha-\left[{ }^{3} \mathrm{H}\right]$ cortisol to $\left[{ }^{3} \mathrm{H}_{3} \mathrm{H}_{2} \mathrm{O}\right.$ ), was associated with hypertension, hypokalemia, and suppression of the renin-angiotensin-aldosterone system. When established on a fixed $\mathrm{Na}^{+} / \mathrm{K}^{+}$intake, dexamethasone, given orally, produced a natriuresis and potassium retention. Plasma renin activity became detectable. When hydrocortisone (10 mg daily s. c. for 4 d) was added, there was marked $\mathrm{Na}^{+}$ retention, a kaliuresis (urinary $\mathrm{Na}^{+} / \mathrm{K}^{+}$falling from 1.2 to 0.15), with suppression of plasma renin activity and an increase in blood pressure. These changes were also seen with the subject on no treatment. Conversion of cortisone to cortisol was not affected.

These results suggest that cortisol acts as a potent mineralocorticoid in $11 \beta$-OHSD deficiency. The major site for the oxidation of cortisol to cortisone is the kidney. In this patient congenital deficiency of $11 \beta$-OHSD results in high intrarenal cortisol levels which then act on renal type I mineralocorticoid receptors. This condition can be treated with dexamethasone, which suppresses cortisol secretion and binds to the type II glucocorticoid receptor.

We suggest that $11 \beta$-OHSD exerts a critical paracrine role in determining the specificity of the type $I$ receptor. In the normal state cortisol is converted by $11 \beta$-OHSD to cortisone which thus allows aldosterone to bind preferentially to the type $I$ receptors in the kidney and gut. In this patient deficiency of $11 \beta$-OHSD results in high intrarenal cortisol concentrations that then bind to the type I receptor.

\section{Introduction}

Impaired conversion of cortisol (compound F) to cortisone (compound $\mathrm{E}$ ) has been associated with low renin, low aldosterone hypertension with hypokalemia in children (known as the syndrome of "apparent mineralocorticoid excess") (1-5).

The interconversion of cortisol and cortisone has been considered to be carried out by $11 \beta$-hydroxysteroid dehydrogenase

Address reprint requests to Professor C. R. W. Edwards, Department of Medicine, Western General Hospital, Crewe Road, Edinburgh EH4 2XU, Scotland.

Received for publication 10 February 1987 and in revised form 21 January 1988.

J. Clin. Invest.

(c) The American Society for Clinical Investigation, Inc.

0021-9738/88/07/0340/10 \$2.00

Volume 82, July 1988, 340-349
(11 $\beta$-OHSD), ${ }^{1}$ a microsomal enzyme system. Recent evidence suggests that the interconversion is a result of the coordinated action of two independent enzymes, a $11 \beta$-hydroxysteroid dehydrogenase and a 11-oxo-steroid reductase $(6,7)$. For the purpose of this study the familiar term $11 \beta$-OHSD will be used to describe the interconversion.

It was the seminal work by Ulick et al. (5) in two hypertensive children, which first demonstrated that there was a defect in the conversion of cortisol to cortisone (detailed further in publications by New and collaborators [2, 8-10]). Since then the syndrome of apparent mineralocorticoid excess has been detected in about 15 children. Five cases have been documented by Shackleton and co-workers $(4,11)$, with individual cases from Fiselier et al. (12), Honour et al. (3), and Harinck et al. (13), and most recently three further cases by Monder, New, and co-workers (14). Other cases have been documented but not published.

The characteristic urinary steroid metabolite profile is well described $(4,14)$. Patients have limited ability to metabolize cortisol to cortisone but can carry out the reverse reaction. As a result the urinary $11 \beta$-hydroxy metabolites of cortisol are elevated (cortols, tetrahydrocortisol [THF] and C-19 steroids) while the 11-oxo metabolites (cortolones and tetrahydrocortisone [THE]) are diminished. In addition there appears to be an alteration in the allo-THF ( $5 \alpha \mathrm{THF})$ to THF ( $5 \beta \mathrm{THF})$ ratio with $5 \alpha$ THF formed in preference to $5 \beta$ THF in most cases. Whether this reflects a true deficiency of $5 \beta$-reductase has not yet been answered (14).

Defective peripheral cortisol metabolism results in a prolonged plasma cortisol half-life, a reduced daily secretion rate, and normal plasma levels. Many of the cases reported have elevated urinary free cortisol levels $(4,8,13)$.

\section{Methods}

\section{Case report}

G.B., a Caucasian male, presented aged 21 with a 2-wk history of altered vision. During the preceding $2 \mathrm{yr}$ he had sustained three episodes of tonsillitis; each time this was associated with carpopedal spasm and perioral paresthesia. He had had polydipsia and nocturia for several years. There was no other past medical history and he had never had his blood pressure recorded previously. He did not smoke, consume alcohol, or take any regular medications. Consumption of exogenous mineralocorticoids such as liquorice was denied. A strong family history of hypertension was noted (see below).

Examination revealed a blood pressure of $200 / 145 \mathrm{mmHg}$ (right arm), 192/140 mmHg (left arm), sinus rhythm with no radial-femoral

1. Abbreviations used in this paper: $\mathrm{CBG}$, cortisol binding globulin; IVU, intravenous urogram; p.d., potential difference; THE, tetrahydrocortisone; THF, tetrahydrocortisol; $11 \beta$-OHSD, $11 \beta$-hydroxysteroid dehydrogenase. 
delay or vascular bruits. The apex beat was positioned normally but heaving in quality. The second heart sound was loud. Fundoscopy showed grade III hypertensive changes. Height was $173 \mathrm{~cm}$; weight 53 $\mathrm{kg}$; secondary sexual characteristics were normal. Chest $\mathrm{x}$-ray was normal; ECG showed voltage criteria for left ventricular hypertrophy.

During an intravenous urogram (IVU) $24 \mathrm{~h}$ after admission he sustained two episodes of ventricular fibrillation treated with D.C. shock. Biochemistry showed a plasma $\mathrm{Na}^{+} 148 \mathrm{mmol} \cdot \mathrm{liter}^{-1}$ (meq/ liter), $\mathrm{K}^{+} 1.7 \mathrm{mmol} \cdot$ liter $^{-1}$, bicarbonate $32 \mathrm{mmol} \cdot$ liter $^{-1}$. Creatinine clearance and 24-h urinary metanephrines were normal. The IVU showed mild bilateral nephrocalcinosis with two renal cysts confirmed on subsequent ultrasonography and computerized tomography. Serum and 24-h urinary calcium were normal. Supine plasma renin activity and aldosterone levels were suppressed at $0.1 \mathrm{ng} \mathrm{ml}^{-1} \mathrm{~h}^{-1}$ (reference range 0.5-1.5) and $<100 \mathrm{pmol} \cdot \operatorname{liter}^{-1}$ (reference range $150-500 \mathrm{pmol}^{-}$liter $\left.^{-1}\right)$, respectively.

Over the next few months control of his blood pressure and hypokalemia was poor despite a variety of antihypertensive medications (atenolol $300 \mathrm{mg}$, captopril $150 \mathrm{mg}$, hydralazine $200 \mathrm{mg}$, amiloride 10 $\mathrm{mg}$, prazosin $25 \mathrm{mg}$, nifedipine retard $40 \mathrm{mg}$, and Sando K $48 \mathrm{mmol}$ per d). He was then referred to this hospital and a diagnosis of $11 \beta$ OHSD deficiency made from urinary steroid metabolites as measured by gas chromatography/mass spectrometry (Table I).

The elevated THF + allo THF/THE ratio is diagnostic of $11 \beta$ OHSD deficiency, the elevated $5 \alpha$ THF (allo THF) $/ 5 \beta$ THF ratio in keeping with other reported cases.

GB was then admitted to the Metabolic Unit for further studies; local Ethical Committee and ARSAC approval was obtained for administration of radioisotopes.

\section{Procedures}

The patient was weighed at 0830 hours each morning after emptying his bladder. Blood pressure was recorded automatically using a commercially available automatic Copal sphygmomanometer (Andrew Stephens, Blackpool, England), which was checked against a random zero sphygmomanometer at weekly intervals.

During all metabolic studies BP was recorded in the supine position at 5-min intervals from 1400 hours to 1500 hours each day. When analyzing blood pressure recordings during the metabolic studies, sta- tistical analysis was performed on consecutive readings from three days, i.e., at least 30 systolic and diastolic recordings, using Student's paired $t$ test.

\section{Assays}

Plasma and urinary free cortisol were measured by radioimmunoassay, using the commercially available Amerlex kit (Amersham International) (15). Corticosterone (16), urinary aldosterone (17), and plasma renin activity (PRA) (18) were measured by modifications of previously reported methods. Plasma aldosterone was measured by the direct radioimmunoassay of Al-Dujaili and Edwards (19), except that (a) sample volume has been reduced to $50 \mu \mathrm{l}$ with a resultant fall in the nonspecific binding, improving assay precision and $(b)$ charcoal separation rather than a double antibody separation has considerably improved the sensitivity at lower values. The lowest detection limit for the assay is now $100 \mathrm{pmol} \mathrm{1}^{-1}$. Plasma and urinary electrolyte and creatinine were measured by an ion selective method using an Astra 4.

Deoxycorticosterone (DOC) assay. Plasma was extracted with 5 vol of freshly distilled dichloromethane, the extract washed with $0.1 \mathrm{M}$ $\mathrm{NaOH}$ and with water before aliquots (equivalent to $100 \mu \mathrm{l}$ plasma) were evaporated to dryness under nitrogen at $45^{\circ} \mathrm{C}$.

The assay used rabbit antiserum (R7-6; St. Bartholomew's Hospital) and tritium label (Amersham International). Because of cross-reactivity with testosterone and progesterone, extracts were purified further by HPLC using a $\mu$ Bondapak $C_{18}$ reverse-phase column with $60: 40$ ( $\mathrm{vol} / \mathrm{vol})$ methanol/water as mobile phase. The appropriate fraction of eluate was collected, methanol evaporated off under nitrogen and the aqueous solution back extracted with dichloromethane. This extract was evaporated to dryness under nitrogen, dissolved in $100 \mu$ assay diluent ( $0.05 \mathrm{M}$ phosphate buffer, $\mathrm{pH} 7$, containing $0.1 \% \mathrm{BSA}),\left[{ }^{3} \mathrm{H}\right]$ $\mathrm{DOC}(\sim 2,000 \mathrm{cpm})$ and antiserum in $100 \mu \mathrm{l}$ assay diluent added; final antiserum dilution 1:20,000. After overnight incubation at $4^{\circ} \mathrm{C}$, bound and unbound DOC were separated using dextran-coated charcoal and supernatant (following centrifugation) counted in Scintran $T$ (BDH Chemicals, Poole, England).

Aliquots from $24 \mathrm{~h}$ urine collections were stored at $-20^{\circ} \mathrm{C}$ and the urinary steroid metabolites analyzed using gas chromatography and gas chromatography/mass spectrometry using previously reported methods $(4,20)$.

Table I. Blood Pressures and Urinary Steroid Metabolites in G.B., His Parents, and Siblings as Compared to 22 Normal Controls Aged 18-55 (16 Males)

\begin{tabular}{|c|c|c|c|c|c|c|c|}
\hline & & G.B. & S.B. & P.B. & N.D. & T.B. & E.B. \\
\hline Blood pressure (mmHg) & & $235 / 125$ & $\begin{array}{c}\text { Father } \\
166 / 102\end{array}$ & $\begin{array}{l}\text { Mother } \\
165 / 92 \\
\end{array}$ & $\begin{array}{c}\text { Sister } \\
125 / 82\end{array}$ & $\begin{array}{l}\text { Brother } \\
134 / 84\end{array}$ & $\begin{array}{l}\text { Brother } \\
135 / 85 \\
\end{array}$ \\
\hline & $\begin{array}{l}\text { reference range (mean } \pm S D) \\
\mu g / 24 h n=22\end{array}$ & & & & & & \\
\hline \multicolumn{8}{|l|}{ Steroid } \\
\hline Androsterone & $2,068 \pm 89.2$ & 10,176 & 700 & 470 & 1,966 & 7,018 & 5,741 \\
\hline Etiocholanolone & $1,690 \pm 874$ & 4,427 & 1,137 & 767 & 2,379 & 6,606 & 6,333 \\
\hline 11-oxo-etiocholanolone & $426 \pm 461$ & 537 & 680 & 534 & 1,059 & 1,257 & 1,155 \\
\hline $11 \beta$-hydroxyandrosterone & $1,058 \pm 875$ & 1,555 & 852 & 799 & 1,821 & 3,510 & 2,513 \\
\hline $11 \beta$-hydroxyetiocholanolone & $396 \pm 272$ & 1,075 & 309 & 686 & 1,037 & 1,270 & 972 \\
\hline (THE) & $2,589 \pm 1,292$ & 537 & 2,435 & 4,414 & 2,545 & 4,619 & 3,675 \\
\hline (THF) & $1,469 \pm 585$ & 2,472 & 2,076 & 3,019 & 1,380 & 3,679 & 2,456 \\
\hline Allo tetrahydrocortisol (allo-THF) & $1,033 \pm 525$ & 4,819 & 1,019 & 1,860 & 839 & 3,716 & 2,367 \\
\hline$\alpha$-cortolone & $913 \pm 386$ & 182 & 513 & 778 & 622 & 874 & 662 \\
\hline$\alpha$-cortol & $303 \pm 100$ & 422 & 342 & 338 & 310 & 690 & 610 \\
\hline $\left.\begin{array}{l}\beta \text {-cortolone } \\
\beta \text {-cortol }\end{array}\right\}$ & $920 \pm 414$ & 537 & 241 & 916 & 310 & 765 & 512 \\
\hline THF + allo THF/THE ratio & $0.97 \pm 0.30$ & 13.57 & 1.27 & 1.10 & 0.87 & 1.60 & 1.31 \\
\hline
\end{tabular}


Synthesis and metabolism of $11 \alpha-\left[{ }^{3} \mathrm{H}\right]$ cortisol. $11 \alpha-\left[{ }^{3} \mathrm{H}\right]$ Cortisol was prepared as described by Hellman et al. (21) but with modifications to improve the radiochemical yield and define the specific activity. The main changes were a threefold increase in the ratio of cortisone-3, 20-bisethylene eetal to sodium $\left[{ }^{3} \mathrm{H}\right]$ borohydride and purification of the final product by thin layer chromatography on silica gel $\mathrm{GF}_{254}(20 \times 20 \mathrm{~cm} \times 0.25 \mathrm{~mm})$ in chloroform-methanol (9:1 by vol). The cortisol band was located under ultraviolet light, scraped from the plate and eluted with ethanol $(1 \times 5 \mathrm{ml} ; 6 \times 1 \mathrm{ml})$. The cortisol concentration in recovered solution (total volume $9 \mathrm{ml}$ ) determined by quantitative high pressure liquid chromatography ( $\mu$ Bondapak $\mathrm{C}_{18}$; mobile phase methanol-water $1: 1$ by volume; calibrated against a standard cortisol solution) was $1.48 \mathrm{mg} / \mathrm{ml}$, and the radioactive concentration determined by scintillation counting was $5.91 \mathrm{MBq} / \mathrm{ml}$. The specific activity was therefore $1.44 \mathrm{GBq} / \mathrm{mmol}$. No cortisone or 11-epicortisol was detected in the purified product (lower limit of detection of either compound was $\mathbf{0 . 5 \%}$ ). The ethanol solution was passed through a $0.2-\mu \mathrm{m}$ filter, aliquoted into sterile vials (1.19 MBq/ vial) and stored at $4^{\circ} \mathrm{C}$.

The measured specific activity was substantially lower than that of the sodium borohydride (2.6 GBq per hydride) due to the well-known primary isotope effect.

With G.B. fasted overnight diuresis was established by an oral water load. When a constant urinary flow rate was achieved, $1.19 \mathrm{MBq}$ $11 \alpha-\left[{ }^{3} \mathrm{H}\right]$ cortisol in $0.36 \mathrm{ml}$ ethanol i.v. was injected as a bolus in $15 \mathrm{ml}$ water. Urine was collected at 15 -min intervals, blood at 15 -min intervals during the first $60 \mathrm{~min}$, then every $30 \mathrm{~min}$ for $120 \mathrm{~min}$. The samples were counted for total ${ }^{3} \mathrm{H}$ and for $\left[{ }^{3} \mathrm{H}\right] \mathrm{H}_{2} \mathrm{O}$ following sublimation using a (Tricarb 4330 series; Packard Instruments, Inc., Downers Grove, IL) liquid scintillation beta counter after correction for quench. Cocktail T (BDH Chemicals) was used as scintillant. Subtraction of $\left[{ }^{3} \mathrm{H}\right] \mathrm{H}_{2} \mathrm{O}$ from total ${ }^{3} \mathrm{H}$ gave a value in counts/min representing activity of the tritiated steroid. Separate experiments were performed with the HPLC system outlined above to demonstrate that the residual radioactivity after sublimation resided in $11 \alpha-\left[{ }^{3} \mathrm{H}\right]$ cortisol. Plots of $\log _{10} 11 \alpha-\left[{ }^{3} \mathrm{H}\right]$ cortisol versus time were made and the slope analyzed by linear regression. Only the elimination phase (time points 45-120 $\mathrm{min}$ ) was studied and expressed as a half-life.

Subtraction potential difference (p.d.). As an index of in vivo mineralocorticoid activity substraction p.d. was measured using an Adrenosonde (Kontron, Vienna, Austria) measuring the p.d. across a steroid insensitive mucosa (buccal mucosa) and subtracting this from a steroid sensitive mucosa (rectum) (22). Subtraction of buccal from rectal p.d. eliminates the nonsteroidal influences of rectal p.d.

The reference electrode was placed on the forearm over an intracutaneous injection of $0.3 \mathrm{ml} 0.9 \%$ saline to eliminate skin p.d. The potential difference was read with the probe electrode placed on either the buccal mucosa $3 \mathrm{~cm}$ from the oral orifice or on the rectal mucosa 8 $\mathrm{cm}$ from the anal margin, $20 \mathrm{ml}$ of $0.9 \%$ saline having been injected into the rectum. This was performed on every second day during the metabolic studies at 1000 hours. Two recordings (which never differed by more than $4 \mathrm{mV}$ ) were made at 20-min intervals and the mean recorded. The normal subtraction p.d. is -5 to $+25 \mathrm{mV}$, with values of 40-80 mV occurring in states of mineralocorticoid excess such as primary aldosteronism (23).

\section{Metabolic balance studies}

To investigate the role of cortisol in producing the hypertension and hypokalemia in our patient, metabolic balance studies were performed on a fixed $\mathrm{Na}^{+} / \mathrm{K}^{+} \operatorname{diet}\left(118 \mathrm{mmol} \mathrm{Na}{ }^{+}, 78 \mathrm{mmol} \mathrm{K} /\right.$ day). In balance it was possible to withdraw all drugs except for nifedipine, amiloride, and Sando K ( $48 \mathrm{mmol})$ with no ill effects apart from mild elevation of blood pressure. The metabolic balance was divided into several studies.

Study 1 involved baseline investigation of the circadian rhythm of cortisol, measurement of other adrenal and gonadal steroids, ACTH and the oral administration of dexamethasone, initially $0.5 \mathrm{mg} 6$ hourly for $48 \mathrm{~h}$, then $1.5 \mathrm{mg} / \mathrm{d}$.
Study 2 was performed with the patient in balance taking $1.5 \mathrm{mg}$ dexamethasone daily. Hydrocortisone $(10 \mathrm{mg}$ ) was then given subcutaneously via a pulsatile NIMR Millhill pump delivering steroid at 15min pulses. $10 \mathrm{mg}$ was chosen as this was the sum of free and conjugated cortisol metabolites excreted in the urine in a 24-h period as determined by GC/MS.

Study $\mathbf{3}$ was performed with the patient on no treatment for $\mathbf{8} \mathrm{d}$ to reproduce the syndrome.

Study 4. Finally cortisone acetate was given orally $(25 \mathrm{mg}$ at 0900 hours, $12.5 \mathrm{mg}$ at 1700 hours).

In study 5 we examined the metabolism of $11 \alpha-\left[{ }^{3} \mathrm{H}\right]$ cortisol given intravenously as a bolus.

\section{Hemodynamic assessment}

With the patient supine on no treatment and fasted overnight, a thermodilution flow directed balloon catheter was sited in the pulmonary artery via the femoral vein and its position confirmed by fluoroscopy. Right atrial pressure (RAP) and cardiac output (CO) were measured, the latter by using a thermodilution technique. Blood pressure (BP) was recorded in the right arm during the procedure using a mercury sphygmomanometer. Systemic vascular resistance (SVR) was then calculated using the formula SVR $=$ BP-RAP $\times 80 / C O\left(\right.$ dyn s$\left.^{-1} \mathrm{~cm}^{-5}\right)$.

\section{Results}

\section{Family data}

Blood pressure recordings were made in the supine position between 0830-0900 hours using a Copal automatic sphygmomanometer in G.B.'s parents and siblings and $24 \mathrm{~h}$ urinary steroid metabolites measured (Table I).

G.B.'s father, S.B., had a 20-yr history of hypertension controlled for the last four years on hydralazine and a beta blocker/diuretic combination. PB, his mother, had hypertension diagnosed at the age of 53 and had been treated with diuretics only. Under supervision all medication was withdrawn from S.B. and P.B. for 4 wk, and they were investigated further. S.B. had normal plasma electrolytes $\left(\mathrm{Na}^{+} 137\right.$ $\mathrm{mmol} \cdot$ liter $^{-1}, \mathrm{~K}^{+} 3.9 \mathrm{mmol} \cdot$ liter $^{-1}$, bicarbonate 28 mmol $\left.\cdot \operatorname{liter}^{-1}\right)$, normal urinary free cortisol $\left(155 \mathrm{nmol} \cdot \mathrm{l}^{-1}\right)$, supine PRA $\left(0.7 \mathrm{ng} \mathrm{ml^{-1 }} \mathrm{h}^{-1}\right)$ and urinary aldosterone (23 nmol/24 h). However G.B.'s mother, PB, had a mild hypokalemic alkalosis $\left(\mathrm{Na}^{+} 137 \mathrm{mmol} \cdot \operatorname{liter}^{-1}, \mathrm{~K}^{+} 3.3 \mathrm{mmol} \cdot\right.$ liter $^{-1}$, bicarbonate $33 \mathrm{mmol} \cdot \operatorname{liter}^{-1}$ ) associated with suppression of the renin angiotensin aldosterone system (supine PRA $0.3 \mathrm{ng}$

Table II. Plasma Steroid, ACTH, and Catecholamine Levels

\begin{tabular}{|c|c|c|c|}
\hline \multirow[b]{2}{*}{ Day } & \multicolumn{2}{|c|}{ Cortisol nmol $\cdot$ liter $^{-1}$} & \multirow{2}{*}{ 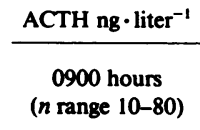 } \\
\hline & $\begin{array}{l}0900 \text { hours } \\
\text { (n range } 180-700 \text { ) }\end{array}$ & $\begin{array}{c}2400 \text { hours } \\
\text { ( } n \text { range }<180)\end{array}$ & \\
\hline 1 & 513 & 156 & 35 \\
\hline 2 & 519 & 290 & 32 \\
\hline 3 & 601 & 217 & 45 \\
\hline Norepinephrine* & $1.3 \mathrm{nmol} \cdot$ liter $^{-1}$ & & (normal <5) \\
\hline Epinephrine* & $0.06 \mathrm{nmol} \cdot$ liter $^{-1}$ & & (normal <1) \\
\hline Testosterone* & $24 \mathrm{nmol} \cdot$ liter $^{-1}$ & & (normal 10-30) \\
\hline Androstenedione* & $3.5 \mathrm{nmol}^{\cdot}$ liter $^{-1}$ & & (normal 2-11) \\
\hline \multicolumn{4}{|c|}{$\begin{array}{l}\text { Dehydroepian- } \\
\text { drosterone }\end{array}$} \\
\hline sulfate* & $11 \mu \mathrm{mol} \cdot$ liter $^{-1}$ & & (normal 2-9) \\
\hline
\end{tabular}

\footnotetext{
* Samples taken at 0900 hours on day 1 .
} 

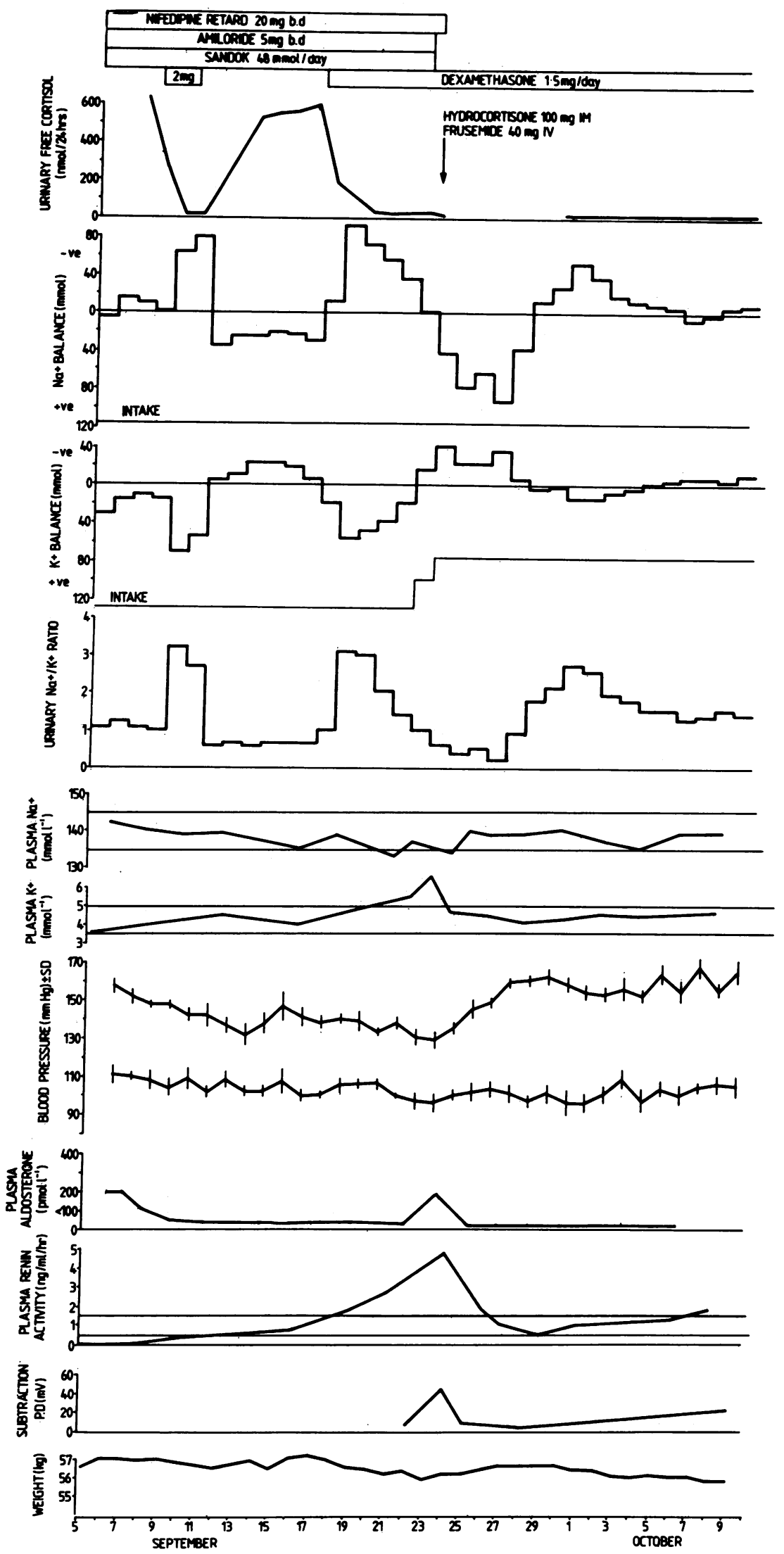

Figure 1. Metabolic balance study 1. Urinary free cortisol, urine and plasma electrolytes, blood pressure, plasma aldosterone, renin activity, subtraction p.d. and weight are shown during acute ( 2 $\mathrm{mg} / \mathrm{d}$ for $48 \mathrm{~h}$ ) and chronic ( $1.5 \mathrm{mg} / \mathrm{d}$ ) dexamethasone therapy. The reference ranges for plasma $\mathrm{Na}^{+}, \mathrm{K}^{+}$and renin activity are indicated. The mean \pm SD of 10 readings for systolic and diastolic blood pressure is charted. 
$\mathrm{ml}^{-1} \mathrm{~h}^{-1}$, urinary aldosterone $5 \mathrm{nmol} / 24 \mathrm{~h}$ ). Despite this metabolic disturbance, urinary free cortisol was normal (272 $\mathrm{nmol} / 24 \mathrm{~h}$ ) as were her urinary steroid metabolites.

As shown, all the siblings had normal blood pressure but their steroid excretion patterns were not entirely normal. Both brothers in addition to G.B. showed high urinary levels of androsterone, etiocholanolone, and its $11 \beta$ - and oxo metabolites (Table I). In the 16 control males (mean age $30.7 \mathrm{yr}$ ) the mean androsterone and etiocholanolone excretions were $2,292 \pm 1131$ (SD) (range 1,016-4,856) and 2,430 \pm 744 (range 1,265-3,772) $\mu \mathrm{g} / 24 \mathrm{~h}$, respectively. One brother, T.B., had a marginally elevated THF + allo THF/THE ratio.

\section{Study 1}

Baseline investigations and dexamethasone suppression. Table II shows that G.B. had a normal cortisol circadian rhythm, normal ACTH levels, plasma catecholamines, testosterone, and androstenedione. Plasma dehydroepiandrosterone sulphate was slightly elevated.

When in balance on his fixed $\mathrm{Na}^{+} / \mathrm{K}^{+}$diet and treated with nifedipine retard $20 \mathrm{mg}$ twice daily, amiloride $5 \mathrm{mg}$ twice daily, and potassium supplements ( $48 \mathrm{mmol} / 24 \mathrm{~h}$ ), dexamethasone $0.5 \mathrm{mg} 6$ hourly was given for $48 \mathrm{~h}$. As shown in Fig. 1 urinary free cortisol suppressed from $628 \mathrm{nmol} / 24 \mathrm{~h}$ to $<30$ $\mathrm{nmol} / 24 \mathrm{~h}$ (reference range $80-450 \mathrm{nmol} / 24 \mathrm{~h}$ ). There was a marked natriuresis with potassium retention, urinary $\mathrm{Na}^{+} / \mathrm{K}^{+}$ ratio rising from 1.2 to 3.3. Plasma electrolytes showed a corresponding change, $\mathrm{Na}^{+}$falling from 143 to $136 \mathrm{mmol} \cdot$ liter $^{-1}$, $\mathrm{K}^{+}$rising from 3.5 to $4.5 \mathrm{mmol} \cdot \operatorname{liter}^{-1}$. Table III shows the response of plasma cortisol, renin activity, deoxycorticosterone, aldosterone, corticosterone, weight and subtraction potential difference during this and subsequent studies. Baseline values were obtained from the day immediately prior to the first dose of dexamethasone. As shown, PRA initially suppressed despite nifedipine and a low dose of amiloride became detectable. Plasma aldosterone over this short period of time remained low as expected following prolonged suppression of the zona glomerulosa. When the urinary free cortisol levels reverted to predexamethasone values maintenance dexamethasone was recommenced $(1.0 \mathrm{mg} 2300$ hours and $0.5 \mathrm{mg} 0900$ hours). Once again this produced a natriuresis and potassium retention, indeed the combination of dexamethasone and amiloride resulted in marked hyperkalemia $\left(\mathrm{K}^{+}\right.$peak 6.8 mmol $\cdot$ liter $^{-1}$ ) and this coincided with and was possibly the cause of the rise in plasma aldosterone. The hyperkalemia was treated by parenteral hydrocortisone (100 mg i.m.), frusemide (40 mg i.v.) and withdrawal of $\mathrm{K}^{+}$and amiloride (Fig. 1). Nifedipine was also stopped. When reestablished in balance on dexamethasone $1.5 \mathrm{mg}$ daily and off all other drugs, G.B. maintained a normal plasma $\mathrm{K}^{+}$, with only a slight rise in blood pressure. On dexamethasone alone, subtraction p.d. remained in the normal range at $3-10 \mathrm{mV}$, as did PRA (0.5-1.5

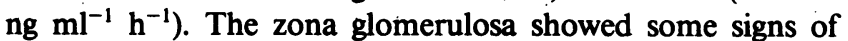
recovery immediately prior to study 2 (plasma aldosterone 140 pmol $\cdot$ liter $\left.^{-1}\right)$.

\section{Study 2}

Hydrocortisone administration. Administration of hydrocortisone $(10 \mathrm{mg} / 24 \mathrm{~h}$ for $4 \mathrm{~d}$ ) when G.B. was in metabolic balance and only on dexamethasone $1.5 \mathrm{mg} / 24 \mathrm{~h}$ produced urinary free cortisol levels similar to those on no treatment. As shown in Fig. 2 this caused marked $\mathrm{Na}^{+}$retention and a kaliuresis with a fall in urinary $\mathrm{Na}^{+} / \mathrm{K}^{+}$ratio from 1.2 to 0.15 . Plasma electrolytes showed corresponding changes, $\mathrm{Na}^{+}$rising from 136 to $145 \mathrm{mmol} \cdot 1$ liter $^{-1}, \mathrm{~K}^{+}$falling from 4.5 to 3.3 $\mathrm{mmol} \cdot$ liter $^{-1}$. As expected there was weight gain and suppression of PRA and plasma aldosterone (Table III). Subtraction p.d. rose to $59 \mathrm{mV}$, indicative of mineralocorticoid excess. In addition there was a highly significant rise in both systolic and diastolic blood pressure (Table IV).

\section{Study 3}

Withdrawal of dexamethasone. When back in $\mathrm{Na}^{+} / \mathrm{K}^{+}$balance on dexamethasone alone, dexamethasone was discontinued for $8 \mathrm{~d}$ (Fig. 3). Urinary free cortisol, which on dexamethasone was $<30 \mathrm{nmol} / 24 \mathrm{~h}$ rose to $450 \mathrm{nmol} / 24 \mathrm{~h}$. There was a kaliuresis and $\mathrm{Na}^{+}$retention with urinary $\mathrm{Na}^{+} / \mathrm{K}^{+}$ratio falling to 0.15 . Plasma $\mathrm{K}^{+}$fell to $2.9 \mathrm{mmol} \cdot \operatorname{liter}^{-1}$ and $\mathrm{Na}^{+}$rose to $146 \mathrm{mmol} \cdot \operatorname{liter}^{-1}$. PRA suppressed once more as did plasma aldosterone (which had risen to 210 pmol liter $^{-1}$ prior to withdrawal of treatment). Similarly subtraction p.d. was elevated at $48 \mathrm{mV}$, a pattern identical to that seen following cortisol administration (Table III). In addition there was a significant rise in diastolic blood pressure (Table IV).

These changes were then reversed on restarting dexamethasone; $1.25 \mathrm{mg}$ dexamethasone/d $(0.75 \mathrm{mg} 2300$ hours, $0.5 \mathrm{mg}$ 0900 hours) was sufficient to suppress urinary free cortisol to $<30 \mathrm{nmol} / 24 \mathrm{~h}$ and prevent hypokalemia.

Table III. Plasma Cortisol (F), Renin Activity (PRA), DOC, Corticosterone (B), Aldosterone (Aldo), Subtraction p.d. and Weight during Metabolic Studies

\begin{tabular}{|c|c|c|c|c|c|c|}
\hline & Reference range & Baseline & $\begin{array}{l}\text { Acute Dexa suppression } \\
(2 \mathrm{mg} / \mathrm{d} \text { for } 48 \mathrm{~h})\end{array}$ & $\begin{array}{c}\text { Dexa } \\
1.5 \mathrm{mg} / \mathrm{d}\end{array}$ & $\begin{array}{c}\text { Dexa } 1.5 \mathrm{mg} / \mathrm{d} \\
+ \text { hydrocortisone } \\
10 \mathrm{mg} / \mathrm{d}\end{array}$ & $\begin{array}{c}\text { No } \\
\text { treatment }\end{array}$ \\
\hline $09.00 \mathrm{~F}$ & 300-700 nmol liter ${ }^{-1}$ & 601 & 39 & 30 & 239 & 367 \\
\hline $09.00 \mathrm{~B}$ & $1.4-15.6 \mathrm{nmol}$ liter $^{-1}$ & 1.2 & 1.0 & 0.4 & 0.5 & 1.1 \\
\hline $09.00 \mathrm{DOC}$ & $150-450$ pmol liter $^{-1}$ & 214 & 223 & 181 & 172 & 220 \\
\hline 09.00 PRA (supine) & $0.5-1.5 \mathrm{ng} \mathrm{AI} \mathrm{ml}^{-1} \mathrm{~h}^{-1}$ & $<0.05$ & 0.39 & 0.50 & $<0.05$ & 0.1 \\
\hline 09.00 Aldo (supine) & $135-500 \mathrm{pmol}$ liter $^{-1}$ & 120 & $<100$ & 140 & $<100$ & $<100$ \\
\hline Subtraction p.d. & $-5 \pm 25 \mathrm{mV}$ & - & 8 & 3 & 59 & 48 \\
\hline Weight, kg & & 57.0 & 56.7 & 56.6 & 57.2 & 57.1 \\
\hline
\end{tabular}

Baseline values were obtained on the day immediately before the first dose of dexamethasone when in metabolic balance. Other values reported refer to the last day of the treatment option described. 

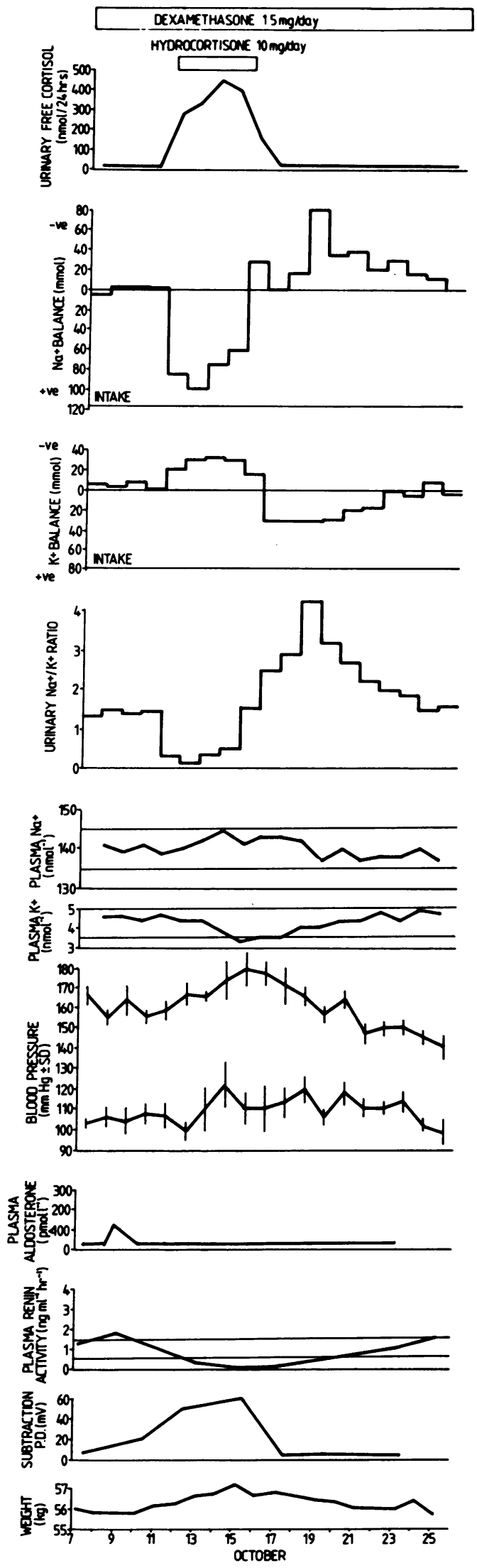

Figure 2. Metabolic balance data, blood pressure, renin activity and subtraction pd. for study 2 . With GB on dexamethasone $1.5 \mathrm{mg} / \mathrm{d}$, the response to hydrocortisone $10 \mathrm{mg} / \mathrm{d}$ for $4 \mathrm{~d}$ is shown.
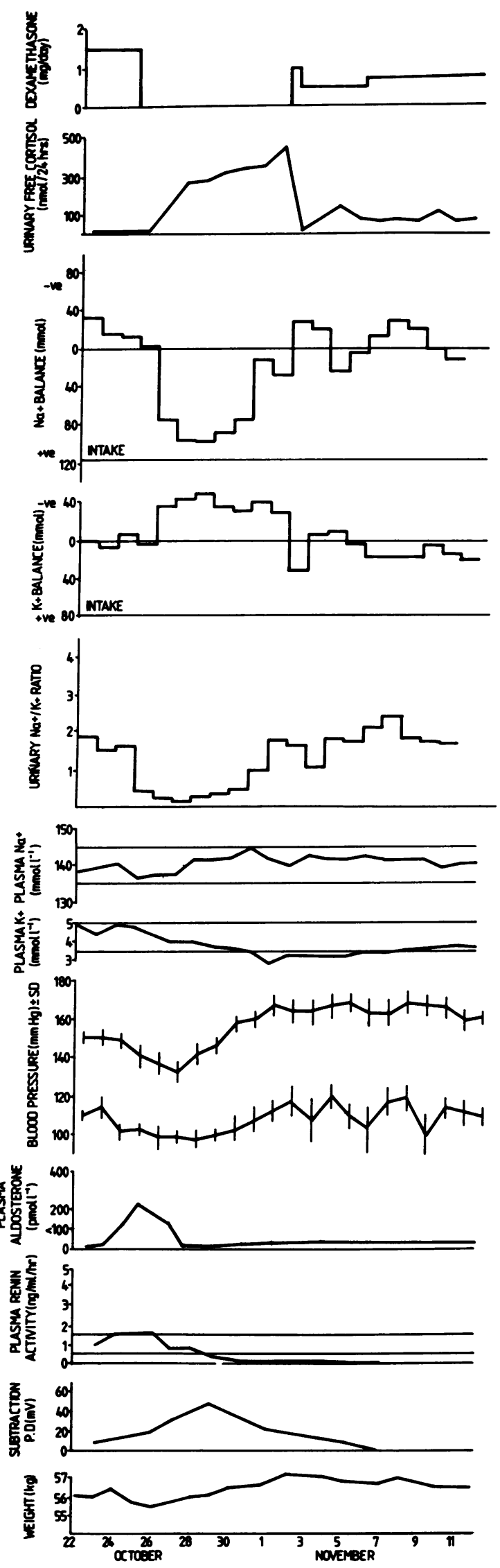

Figure 3. Metabolic balance study 3. Dexamethasone was discontinned for $8 \mathrm{~d}$.

Cortisol-Cortisone Shuttle

345 
Table IV. Mean Blood Pressure Readings during Metabolic Studies

\begin{tabular}{|c|c|c|}
\hline Treatment option & Systolic B.P. $\mathrm{mmHg}$ & Diastolic B.P. $\mathrm{mmHg}$ \\
\hline & mean $\pm S D$ & mean $\pm S D$ \\
\hline \multicolumn{3}{|l|}{ A Dexamethasone } \\
\hline$(1.5 \mathrm{mg} / \mathrm{d})$ & $161 \pm 7$ & $105 \pm 7$ \\
\hline \multicolumn{3}{|l|}{$\begin{array}{c}\text { B Dexamethasone } \\
(1.5 \mathrm{mg} / \mathrm{d})\end{array}$} \\
\hline $\begin{array}{l}\text { Hydrocortisone } \\
(10 \mathrm{mg} / \mathrm{d})\end{array}$ & $177 \pm 8$ & $114 \pm 12$ \\
\hline C No treatment & $163 \pm 6$ & $112 \pm 8$ \\
\hline \multicolumn{3}{|l|}{$P$ value } \\
\hline & Systolic & Diastolic \\
\hline A vs. $B$ & $<0.001$ & $<0.001$ \\
\hline A vs. $\mathrm{C}$ & NS & $<0.001$ \\
\hline
\end{tabular}

\section{Study 4}

Administration of cortisone acetate. This study was performed $12 \mathrm{~m}$ after study 3. During this period blood pressure had been measured twice weekly by G.B. himself and averaged 110/70 $\mathrm{mmHg}$. Blood pressure had been controlled in the interim on dexamethasone $1.25 \mathrm{mg} / \mathrm{d}$, captopril $25 \mathrm{mg}$ b.d., frusemide 40 $\mathrm{mg} / \mathrm{d}$. When reassessed at this visit, he had a blood pressure of $115 / 82 \mathrm{mmHg}$ supine and $102 / 66 \mathrm{mmHg}$ erect suggesting over treatment with frusemide and captopril. These were discontinued $11 \mathrm{~d}$ before the administration of cortisone acetate.

G.B. was once more established on the same $\mathrm{Na}^{+} / \mathrm{K}^{+}$diet, and dexamethasone $1.25 \mathrm{mg} / \mathrm{d}$ was continued. When in metabolic balance cortisone acetate $37.5 \mathrm{mg} / \mathrm{d}$ (25 mg 0900 hours, $12.5 \mathrm{mg} 1700$ hours) was given orally for $3 \mathrm{~d}$. This resulted in high urinary free cortisol levels with associated $\mathrm{Na}^{+}$retention though only a moderate kaliuresis (Fig. 4). Before administration of cortisone there was activation of the renin-angiotensinaldosterone system (PRA $13.4 \mathrm{ng} \mathrm{m}^{-1} \mathrm{~h}^{-1}$, urinary aldosterone $74.3 \mathrm{nmol} / 24 \mathrm{~h}$ ) which was in keeping clinically with over treatment. After $3 \mathrm{~d}$ of cortisone acetate PRA fell to $3.4 \mathrm{ng}$ $\mathrm{ml}^{-1} \mathrm{~h}^{-1}$, urinary aldosterone to $4 \mathrm{nmol} / 24 \mathrm{~h}$. Both systolic and diastolic blood pressure rose during this period as shown in Table V.

During the first $24 \mathrm{~h}$ of cortisone acetate administration, plasma cortisol, measured throughout the day showed two distinct peaks $\left(720 \mathrm{nmol} \cdot\right.$ liter $^{-1}$ at 1000 hours and 680 $\mathrm{nmol} \cdot$ liter $^{-1}$ at 1800 hours) indicating that G.B. is able to convert cortisone to cortisol.

\section{Study 5}

Metabolism of $11 \alpha-\left[{ }^{3} H\right]$ cortisol. This was performed with G.B. taking dexamethasone $1.25 \mathrm{mg} / \mathrm{d}$ only, and off all other medication for over $3 \mathrm{wk}$. A preliminary study in a normal volunteer showed that dexamethasone therapy did not alter plasma and urinary total ${ }^{3} \mathrm{H}$ and $\left[{ }^{3} \mathrm{H}\right] \mathrm{H}_{2} \mathrm{O}$ levels (data not shown). Similarly in vitro dexamethasone was shown by Lugg et al. to have no effect on $11 \beta$-OHSD activity (24).

The half-life of $11 \alpha-\left[{ }^{3} \mathrm{H}\right]$ cortisol in G.B. is prolonged at 131 min. In eight normal volunteers the mean plasma half-life was $40.4 \pm 5.3 \mathrm{~min}$, which is in agreement with that found by Hellman et al. (21). When $11 \alpha-\left[{ }^{3} \mathrm{H}\right]$ cortisol is oxidized by $11 \beta-$
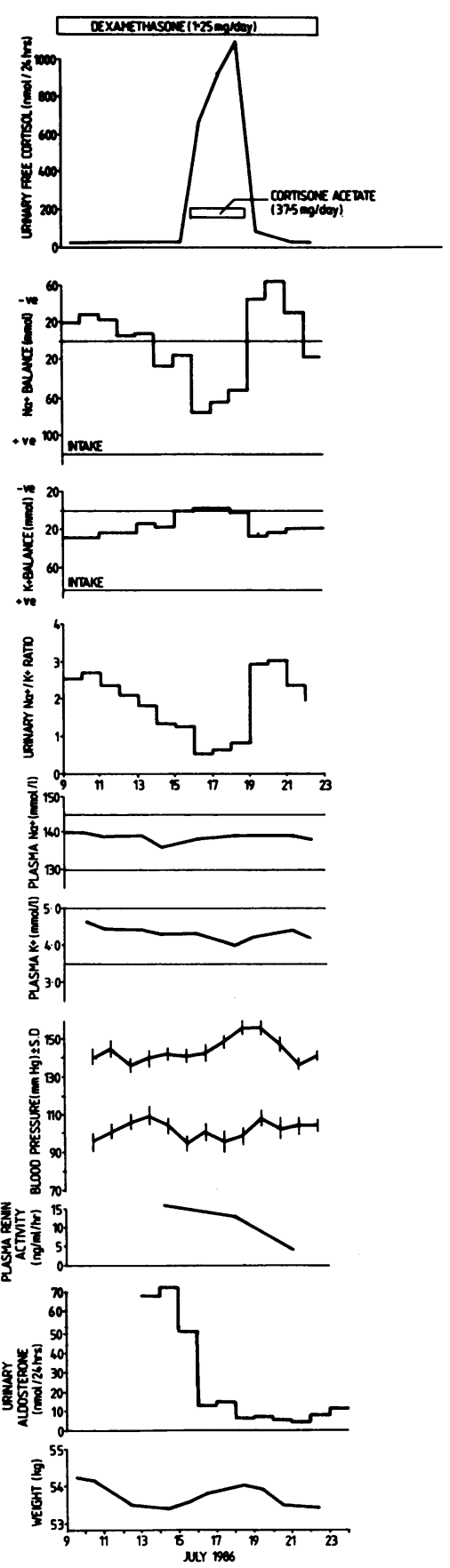

Figure 4. Metabolic balance study 4 . Changes in metabolic parameters and blood pressure are shown following the administration of cortisone acetate $37.5 \mathrm{mg} /$ day for $3 \mathrm{~d}$.

OHSD equimolar amounts of $\left[{ }^{3} \mathrm{H}\right] \mathrm{H}_{2} \mathrm{O}$ and cortisone are produced. G.B. is unable to carry out this reaction as shown by the failure to produce $\left[{ }^{3} \mathrm{H}\right] \mathrm{H}_{2} \mathrm{O}$ in both his plasma and urine (Figs. 5 and 6).

Hemodynamic results. Heart rate, blood pressure, cardiac output (CO) and systemic vascular resistance (SVR) were measured in the erect and supine position. The mean of three readings recorded at 10 -min intervals was taken. In the supine position heart rate was 116 beats/min, mean arterial pressure $149 \mathrm{mmHg}, \mathrm{CO}$ elevated at $8.81 / \mathrm{min}$ (references 4-6), and SVR 1,341 dyn $\mathrm{s}^{-1} \mathrm{~cm}^{-5}$ (references 800-1,400). In the erect posture, heart rate rose to 154 beats/min, MAP was 136 $\mathrm{mmHg}, \mathrm{CO}$ was 4.3 liters/min and SVR elevated at 2,578 dyn $\mathrm{s}^{-1} \mathrm{~cm}^{-5}$. 
Table V. Blood Pressure during Cortisone Acetate Administration

\begin{tabular}{ccc}
\hline Treatment option & Systolic BP mmHg & Diastolic BP mmHg \\
\hline & mean $\pm S D$ & mean $\pm S D$ \\
A Dexamethasone $1.25 \mathrm{mg} / \mathrm{d}$ & $142 \pm 3$ & $99.7 \pm 6$ \\
B Dexamethasone $1.25 \mathrm{mg} / \mathrm{d}$ & & \\
Cortisone acetate $37.5 \mathrm{mg}$ & $153.8 \pm 5$ & $102.3 \pm 6$ \\
$P$ value A vs. B (paired $t$ test) & $<0.001$ & $\mathrm{NS}$ \\
\hline
\end{tabular}

\section{Discussion}

It is not surprising that patients with $11 \beta$-hydroxysteroid dehydrogenase deficiency with hypertension, hypokalemic alkalosis, and suppressed plasma renin and aldosterone levels should have been described as having the syndrome of apparent mineralocorticoid excess. Extensive studies however, using a variety of mineralocorticoid bioassays have failed to demonstrate any evidence of a circulating mineralocorticoid excess (2). The cause of the syndrome, which has previously only been described in children, and which is occasionally fatal, remains unclear $(1,3,5,12)$.

Marver reported in $1978(25)$ that $5 \alpha$-dihydrocortisol potentiated the action of aldosterone in an animal model, but although $5 \alpha$-dihydrocortisol levels were elevated in reported cases these fell at puberty despite continuation of the syndrome (5). When $5 \alpha$-dihydrocortisol was infused in such patients the syndrome could not be reproduced (10).

Detailed metabolic balance studies by New's group have indicated the important role of cortisol in $11 \beta$-OHSD deficiency. Their work has suggested that in these patients cortisol was acting as a mineralocorticoid and this effect could be blocked by spironolactone $(9,10)$. They postulated a receptor defect with an abnormal receptor recognizing cortisol as a mineralocorticoid. This syndrome is familial and this hypothesis would presumably require two genetic defects, one relating to the enzyme and the other to the receptor abnormality (assuming that these are not linked).

$11 \beta$-OHSD occurs in many tissues in man, not only the liver (26) and kidney (27) but also placenta (28), gastrointestinal tract (29), prostate, muscle, lung, and thyroid (27). The "enzyme" has recently been shown to exist as two distinct hydroxy-dehydrogenase and reductase enzymes (6). As glucoand/or mineralocorticoid activity is dependent upon an $11 \beta$ hydroxyl group at the $\mathrm{C}-11$ position then $11 \beta$-OHSD exerts a critical role in the above tissues in regulating the amount of

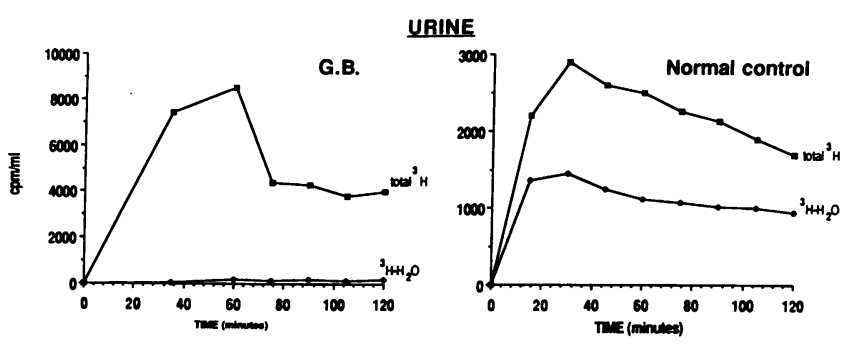

Figure 5. Plasma total ${ }^{3} \mathrm{H}$ and $\left[{ }^{3} \mathrm{H}\right] \mathrm{H}_{2} \mathrm{O}$ in $\mathrm{GB}$ and age matched control on the same $\mathrm{Na}^{+}$intake following $1.19 \mathrm{MBq} 11 \alpha-\left[{ }^{3} \mathrm{H}\right]$ cortisol i.v. at time $=0 \mathrm{~min}$.

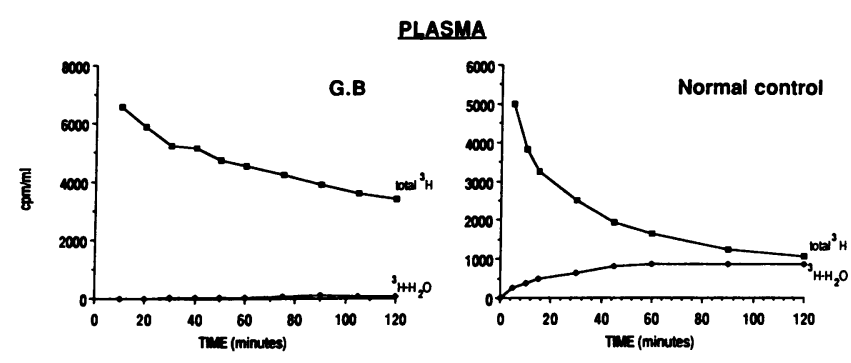

Figure 6. Urinary total ${ }^{3} \mathrm{H}$ and $\left[{ }^{3} \mathrm{H}_{3} \mathrm{H}_{2} \mathrm{O}\right.$ in $\mathrm{GB}$ and the same age matched control following $11 \alpha-\left[{ }^{3} \mathrm{H}\right]$ cortisol given at time $=0 \mathrm{~min}$.

"active steroid" exposed to that tissue by shuttling between the hydroxyl and keto groups. Activities differ markedly in different tissues; the liver, for instance, is strongly reductive (cortisone-cortisol) and dependent upon NADPH (30), the kidney oxidative (cortisol-cortisone) and dependent upon NADP (27). Alteration in enzyme activity within different tissues may reflect a different enzyme or altered redox potential (hence NADPH/NADP ratio) therein.

This study describes the first adult case of $11 \beta$-OHSD deficiency. The metabolic balance studies show that cortisol acted as a potent mineralocorticoid on the kidney (and gastrointestinal tract) causing $\mathrm{Na}^{+}$retention and hypertension with hypokalemia. The profound hypokalemia in addition to causing tetany (as previously seen in other enzymatic forms of mineralocorticoid hypertension, e.g., 17 $\alpha$-hydroxylase deficiency [31]), proved to be life-threatening. Nephrocalcinosis and renal cysts were also seen in the first reported case of Liddle's syndrome (32), and could possibly also relate to chronic hypokalemia. Dexamethasone was able to reverse the hypokalemia, by suppressing the hypothalamic-pituitary adrenal axis, caused a natriuresis and was associated with a lower, but not normal blood pressure, providing a new therapeutic approach in this patient. Only the conversion of cortisol to cortisone was impaired as shown by his failure to metabolize $11 \alpha-\left[{ }^{3} \mathrm{H}\right]$ cortisol, and normal production of cortisol following oral cortisone acetate.

Several studies indicate that there is a genetic basis for this syndrome $(4,14)$. Urinary steroid metabolites in G.B.'s parents on no treatment were normal. The finding of a mild hypokalemic alkalosis with suppression of the renin-angiotensin-aldosterone axis in G.B.'s mother is of considerable interest, and raises the question whether a very subtle abnormality in $11 \beta$-OHSD could be responsible for her condition. The urinary steroid excretion values for G.B.'s brothers were notable but we hesitate to term them abnormal. Like G.B., the brothers had evidence of high androgen production through elevated excretions of androsterone and etiocholanolone. Most notable was the high excretion of $11 \beta$-hydroxyandrosterone, which could reflect increased activity of side-chain cleavage in cortisol metabolism or substantial $11 \beta$-hydroxylation of testosterone and androstenedione. Apart from T.B., the THF + alloTHF/THE ratios were normal.

The hemodynamic data indicate a "hyperdynamic circulation" with a high resting cardiac output and normal systemic vascular resistance. This has been described in other patients with "mineralocorticoid excess" states such as primary aldosteronism (33). A sinus tachycardia had been noted since discontinuing beta blockade 12 mo earlier. On adopting the erect 
posture the heart rate increased and cardiac output fell by $50 \%$, suggesting a noncompliant left ventricle as seen in ventricular hypertrophy.

Although Srivastava et al., measuring cortisol/cortisone ratios in severe liver and renal disease, suggest that the kidney is a major source of cortisone (34), the only direct evidence as to the contribution made by the kidney comes from Hellman et al. (21). After isotopic studies using $\left[{ }^{14} \mathrm{C}\right]$ cortisol and $11 \alpha$ $\left[{ }^{3} \mathrm{H}\right]$ cortisol they concluded that the kidney was responsible for $10 \%$ of the total oxidation of cortisol to cortisone.

The recent cloning of the human mineralocorticoid receptor by Arriza et al. (35) has shown remarkable homology between the human glucocorticoid receptor and the human mineralocorticoid receptor. This receptor appears to have similar affinities in vitro for aldosterone, corticosterone, and cortisol, suggesting that something other than receptor structure is important in determining its specificity. Funder had suggested that this may be renal extravascular cortisol binding globulin (CBG) (36). However in recent studies using 10-d-old rats (which have very low levels of $\mathrm{CBG}$ ), the in vivo specificity for the type I receptor was maintained despite much higher levels of corticosterone than aldosterone (37). We postulate that the oxidation of cortisol to cortisone (corticosterone to 11-dehydrocorticosterone in the rat) by renal $11 \beta$-OHSD is critical in determining the intrarenal concentration of active glucocorticoid, and hence the specificity of the type I receptor. Deficiency of renal $11 \beta$-OHSD allows cortisol to act in preference to aldosterone on the mineralocorticoid receptor causing hypertension and hypokalemia. An indication of the abnormal renal handling of cortisol is the moderate elevation of urinary free cortisol in proportion to total cortisol metabolite excretion in the condition, despite normal plasma cortisol levels and a prolonged cortisol half-life. This, through negative feedback control, lowers ACTH and hence cortisol production. If our hypothesis is true this would suggest that this unique biological experiment has disclosed a previously unknown paracrine mechanism by which the kidney protects itself from the mineralocorticoid action of cortisol.

This syndrome indicates the quite striking results of a congenital disturbance of this cortisol-cortisone shuttle. Our recent studies have shown that the sodium retaining effects of liquorice are due to an acquired inhibition of this mechanism and not to a direct effect on renal type I receptors (38). It remains to be seen if more subtle defects in this mechanism are important in other types of hypertension.

\section{Acknowledgments}

We would like to thank I. Nairn, J. Grieve, and the Metabolic Unit staff for their assistance, S. Atherden, and B. Williams for their help in analyzing the above samples, Dr. P. Down for referring this patient and his help in the management of the case. In addition we are grateful to Medical Illustration for their expertise, and B. Beattie and G. Proven for their secretarial help.

Dr. Stewart held the Cruden Medical Fellowship (Scottish Hospital Endowment Trust) and is now a Medical Research Council training fellow. Dr. Shackleton was the recipient of National Institutes of Health grant AM-34400.

\section{References}

1. Werder, E., M. Zachmann, J. A. Vollmin, R. Veyrat, and A. Prader. 1974. Unusual steroid excretion in a child with low renin hypertension. Res. Steroids. 6:385-389.
2. Ulick, S., L. C. Ramirez, and M. I. New. 1977. An abnormality in steroid reductive metabolism in a hypertensive syndrome. J. Clin. Endocrinol. Metab. 44:799-802.

3. Honour, J. W., M. J. Dillon, M. Levin, and V. Shah. 1983. Fatal, low renin hypertension associated with a disturbance of cortisol metabolism. Arch. Dis. Childhood. 58:1018-1020.

4. Shackleton, C. H. L., J. Rodriguez, E. Arteaga, J. M. Lopez, and J. S. D. Winter. 1985. Congenital $11 \beta$-hydroxysteroid dehydrogenase deficiency associated with juvenile hypertension. Corticosteroid metabolite profiles of four patients and their families. Clin. Endocrinol. 22:701-712.

5. Ulick, S., L. S. Levine, P. Gunczler, Z. Giovanni, L. C. Ramirez, W. Rauh, A. Rosler, H. L. Bradlow, and M. I. New. 1979. A syndrome of apparent mineralocorticoid excess associated with defects in the peripheral metabolism of cortisol. J. Clin. Endocrinol. Metab. 49:757-764.

6. Abramovitz, M., C. L. Branchaud, and B. E. P. Murphy. 1982. Cortisol-cortisone intercoversion in human fetal lung: contrasting results using explant and monolayer cultures suggest that $11 \beta$-hydroxysteroid dehydrogenase (E.C. 1.1.1.146) comprises two enzymes. $J$. Clin. Endocrinol. Metab. 54:563-568.

7. Phillipou, G., and B. A. Higgins. 1985. A new defect in the peripheral conversion of cortisone to cortisol. J. Steroid Biochem. 22:435-436.

8. New, M. I., L. S. Levine, E. G. Biglieri, J. Pareira, and S. Ulick. 1977. Evidence for an unidentified steroid in a child with apparent mineralocorticoid hypertension. J. Clin. Endocrinol. Metab. 44:924933.

9. New, M. I., S. E. Oberfield, R. Carey, F. Greig, S. Ulick, and L. S. Levine. 1982. A genetic defect in cortisol metabolism as the basis for the syndrome of apparent mineralocorticoid excess. In Endocrinology of Hypertension. F. Mantero, E. G. Biglieri, and C. R. W. Edwards, editors. Academic Press, London/New York. 85-101.

10. Oberfield, S. E., L. S. Levine, R. M. Carey, F. Greig, S. Ulick, and M. I. New. 1983. Metabolic and blood pressure responses to hydrocortisone in the syndrome of apparent mineralocorticoid excess. $J$. Clin. Endocrinol. Metab. 56:332-339.

11. Shackleton, C. H. L., J. W. Honour, M. J. Dillon, C. Chantler, and R. W. A. Jones. 1980. Hypertension in a four year old child. Gas chromatographic and mass spectrometric evidence for deficient hepatic metabolism of steroids. J. Clin. Endocrinol. Metab. 50:786-792.

12. Fiselier, T. J. W., B. J. Otten, L. A. H. Monnens, J. W. Honour, and P. J. J. Van Munster. 1982. Low-renin, low-aldosterone hypertension and abnormal cortisol metabolism in a 19 month old child. Hormone Res. 16:107-114.

13. Harinck, H. I. J., P. Van Brummelen, A. P. Van Seters, and A. J. Moolenaar. 1984. Apparent mineralocorticoid excess and deficient $11 \beta$-oxidation of cortisol in a young female. Clin. Endocrinol. 12:505-514.

14. Monder, C., C. H. L. Shackleton, H. L. Bradlow, M. I. New, E. Stoner, F. Iohan, and V. Lakshmi. 1986. The syndrome of apparent mineralocorticoid excess: its association with $11 \beta$-dehydrogenase and $5 \beta$-reductase deficiency and some consequences for corticosteroid metabolism. J. Clin. Endocrinol. Metab. 63:550-557.

15. Gough, R. M., and G. E. Ellis. 1981. The radioimmunoassay of cortisol in urine. Difficulties experienced in the development of an assay, and problems of specificity observed with commercial reagents supplied as kits. Clin. Biochem. 14:74-81.

16. Al-Dujaili, E. A. S., B. C. Williams, and C. R. W. Edwards. 1981. The development and application of a direct radioimmunoassay for corticosterone. Steroids. 37:157-176.

17. Al-Dujaili, E. A. S., and C. R. W. Edwards. 1981. Development and application of a simple radioimmunoassay for urinary aldosterone. Clin. Chim. Acta. 116:277-287.

18. Haber, E., T. Koerner, L. B. Page, B. Kliman, and A. Purnode. 1969. Application of a radioimmunoassay for angiotensin I to the physiological measurement of plasma renin activity in normal human subjects. J. Clin. Endocrinol. Metab. 33:52-62. 
19. Al-Dujaili, E. A. S., and C. R. W. Edwards. 1981. Optimisation of a direct radioimmunoassay for plasma aldosterone. J. Steroid Biochem. 14:481-487.

20. Shackleton, C. H. L. 1986. Profiling steroid hormones and urinary steroids. J. Chromatogr. 379:91-156.

21. Hellman, L., F. Nakada, B. Zumoff, D. Fukushima, H. L. Bradlow, T. F. Gallagher. 1971. Renal capture and oxidation of cortisol in man. J. Clin. Endocrinol. 33:52-62.

22. Skrabal, F., J. Aubock, C. R. W. Edwards, and H. Braunsteiner. 1978. Subtraction potential difference: in vivo assay for mineralocorticoid activity. Lancet. i:298-302.

23. Skrabal, F., G. Finkenstedt, R. Gasser, G. Bartsch, and W. Zechman. 1983. Primary aldosteronism and other mineralocorticoid excess syndromes in hypertension. Incidence, screening and diagnosis. In Mineralocorticoids and Hypertension. W. Kaufman, G. Wambach, A. Helber, and K. A. Meurer, editors. Springer-Verlag, Heidelberg, FRG. 143-154.

24. Lugg, M. A., and T. E. Nicolas. 1978. The effect of dexamethasone on the activity of $11 \beta$-hydroxysteroid dehydrogenase in the foetal rabbit lung during the final stage of gestation. J. Pharm. Pharmacol. 30:587-589.

25. Marver, D., and I. S. Edelman. 1978. Dihydrocortisol: a potential mineralocorticoid. J. Steroid Biochem. 9:1-7.

26. Lakshmi, V., and C. Monder. 1985. Extraction of $11 \beta$-hydroxysteroid dehydrogenase from rat liver microsomes by detergents. J. Steroid Biochem. 22:331-340.

27. Jenkins, J. S. 1965. The metabolism of cortisol by human extrahepatic tissues. J. Endocrinol. 34:51-56.

28. Lopez-Bernal, A., A. P. F. Flint, A. B. M. Anderson, and A. C. Turnbull. 1980. 11 $\beta$-hydroxysteroid dehydrogenase activity (E.C. 1.1.1.146) in human placenta and decidua. J. Steroid Biochem. 13:1081-1087.
29. Burton, A. F., and F. H. Anderson. 1983. Inactivation of corticosteroids in intestinal mucosa by $11 \beta$-hydroxysteroid: NADP oxidoreductase (E.C. 1.1.1.146). Am. J. Gastroenterol. 78:627-631.

30. Bush, I. E. 1969. $11 \beta$-hydroxysteroid dehydrogenase: contrast between studies in vivo and studies in vitro. Adv. Biosci. 3:23-39.

31. Biglieri, E. G., M. A. Herron, and N. Brust. 1966. 17-Hydroxylation defect in man. J. Clin. Invest. 45:1946-1954.

32. Liddle, G. W., T. Bledsoe, and W. S. Coppage. 1963. A familial renal disorder simulating primary aldosteronism but with negligible aldosterone secretion. Trans. Assoc. Am. Phys. 76:199-213.

33. Tarazi, R. C., M. M. Ibrahim, E. L. Bravo, and H. P. Dustan. 1973. Haemodynamic characteristics of primary aldosteronism. $N$. Engl. J. Med. 289:1330-1335.

34. Srivastava, L. S., E. E. Werk, K. Thrasher, L. J. Sholiton, R. Kozera, W. Nolten, and H. C. Knowles. 1973. Plasma cortisone as measured by radioimmunoassay. J. Clin. Endocrinol. Metab. 36:937943.

35. Arriza, J. L., C. Weinberger, G. Cerelli, T. M. Glaser, B. L. Handelin, D. E. Housman, and R. M. Evans. 1987. Cloning of human mineralocorticoid receptor complementary DNA: Structural and functional kinship with the glucocorticoid receptor. Science (Wash. DC). 237:268-275

36. Funder, J. W. 1985. On mineralocorticoid and glucocorticoid receptors. In Adrenal Cortex. D. C. Anderson and J. S. D. Winter, editors. Butterworths, London. 86-95.

37. Sheppard, K., and G. W. Funder. 1987. Mineralocorticoid specificity of renal type I receptors: in vivo binding studies. Am. J. Physiol. 252:E224-E229.

38. Stewart, P. M., A. M. Wallace, R. Valentino, D. Burt, C. H. L. Shackleton, and C. R. W. Edwards. 1987. Mineralocorticoid activity of liquorice: 11-Beta-hydroxysteroid dehydrogenase deficiency comes of age. Lancet. ii:821-824. 